\title{
Infundibular Segment of the Fallopian Tube
}

National Cancer Institute

\section{Source}

National Cancer Institute. Infundibular Segment of the Fallopian Tube. NCI Thesaurus. Code C32800.

The funnel shaped portion of the fallopian tube proximal to the fimbrial segment and most distal to the uterus. 